\title{
ARE IMPROVEMENTS MAINTAINED AFTER IN-HOME PULMONARY TELEREHABILITATION FOR PATIENTS WITH CHRONIC OBSTRUCTIVE PULMONARY DISEASE?
}

\author{
NICOLE MARQUIS PT, PHD ${ }^{1}$, PIERRE LARIVÉE MD ${ }^{2}$, MARIE-FRANCE DUBOIS PHD ${ }^{1}$, \\ MICHEL TOUSIGNANT PT, PHD $^{1}$
}

\author{
${ }^{1}$ RESEARCH CENTRE ON AGING, UNIVERSITY INSTITUTE OF GERIATRICS OF SHERBROOKE, UNIVERSITÉ DE \\ SHERBROOKE, SHERBROOKE, QUEBEC, CANADA \\ ${ }^{2}$ RESPIRATORY DIVISION, DEPARTMENT OF MEDICINE, FACULTY OF MEDICINE AND HEALTH SCIENCES, \\ UNIVERSITÉ DE SHERBROOKE, SHERBROOKE, QUEBEC, CANADA
}

\section{ABSTRACT}

This study investigated if improvements can be maintained over 24 weeks when in-home pulmonary telerehabilitation is combined with asynchronous self-management education for Chronic Obstructive Pulmonary Disease (COPD). Twentythree community-living elders with moderate to very severe COPD participated in a pre/post-intervention study. Over 8 weeks, they had access to self-learning capsules on self-management, received 15 in-home teletreatment sessions and were encouraged to gradually engage in unsupervised sessions. Participants were assessed before the intervention (T1), immediately after the intervention (T2), and 6 months later (T3). Outcome measures were (1) exercise tolerance (6-minute walk test [6MWT]), Cycle Endurance Test [CET]), and (2) quality of life (Chronic Respiratory Questionnaire [CRQ]). Although there were significant improvements after 8 weeks of pulmonary telerehabilitation on the 6MWT, CET and three of four CRQ domains, none of these improvements were maintained after 6 months and scores returned to their baseline values (all $p$ values $>0.05$ when comparing T3 with T1). While pulmonary telerehabilitation is possible and has a positive impact on patients with moderate to very severe COPD, improvements were not maintained in the long-term even when physical therapy was accompanied by self-management education.

Keywords: COPD, exercise tolerance, pulmonary rehabilitation, quality of life, telehealth technology, telerehabilitation,

videoconference

Although pulmonary rehabilitation (PR) is recognized as an integral part of the management of Chronic Obstructive Pulmonary Disease (COPD) to improve exercise tolerance and quality of life and reduce symptoms (Bourbeau et al., 2003; Labrecque et al., 2011; Lacasse, Martin, Lasserson, \& Goldstein, 2007; Lacasse et al., 1996), studies on the durability of positive changes are lacking. When looking at the perspective of maintaining improvements, they seem to decrease to near baseline over the long term (Lacasse, Maltais, \& Goldstein, 2004). Previous studies comparing long-term effectiveness between control and rehabilitation groups showed that the difference between the two groups became smaller with time (Maltais et al., 2008; Strijbos, Postma, van Altena, Gimeno, \& Koëter, 1996; Wijkstra et al.,
1995). For example, home-based PR may produce more sustained benefits over 18 months than an outpatient hospital-based PR program but, these beneficial effects tend to decrease over time (Strijbos et al., 1996). In this context, the problem of maintaining improvements remains unsolved.

Accompanying physical therapy exercise training with education on self-management may be one way to enhance maintenance of improvements after PR for patients with COPD. Education on self-management may (1) change patients' health behaviour and adjust their habits for optimal function, (2) improve day-to-day control of their disease, and (3) improve their well-being (Bourbeau et al., 2003; Bourbeau \& van der Palen, 2009). Conventionally, education is done in-person in an outpatient group setting 
but, according to Moroz (2007), the interaction does not need to be done personally to be effective; it can also be done using technology. Virtual programs using Internet technology for education on self-management could also increase accessibility and provide patients with tools to help them increase their knowledge and skills to better selfmanage their own health and have short- and long-term positive impacts post-PR (Nguyen et al., 2008). Indeed, telehealth technology was employed in one study using videoconferencing to deliver educational material on selfmanagement in real time from a center to various remote regions (Stickland et al., 2011). Other studies investigated the use of online programs with chatting or email support for self-management for patients with COPD (Lorig, Ritter, Laurent, \& Plant, 2006; Nguyen, Carrieri-Kohlman, Rankin, Slaughter, \& Stulbarg, 2005). Satisfaction and improvement on dyspnea symptoms and quality of life were observed after such education programs (Lorig et al., 2006; Nguyen et al., 2008). Self-management programs can be delivered remotely to patients and still have positive impacts on their quality of life after the program, but none of the studies looked at long-term impacts of this kind of education programs.

As part of a pre-experimental study investigating the effectiveness of pulmonary telerehabilitation (i.e., physiotherapy exercise training supervised remotely by a therapist via a videoconferencing system) on exercise tolerance and quality of life, we wished to explore strategies aimed at encouraging the participant to pursue the exercises and adequate self-management at the end of treatment. We therefore provided self-management education through narrative health capsules available via the computer workstation. We combined this with a second strategy for which the supervised teletreatment sessions were withdrawn gradually and replaced with unsupervised sessions to encourage the participant to do exercises alone.

Teletreatment had a positive impact on exercise tolerance and quality of life as it was explored with a feasibility study $(n=3)$ conducted by our research team (Tousignant et al. 2012). The purpose here is to investigate if improvements in exercise tolerance and quality of life were sustained 6 months following the end of the program for people with moderate to very severe COPD. We hypothesized that the two strategies we put in place during treatment would favor the pursuit of exercise and adequate self-management of COPD, thus leading to the maintenance of the positive impacts of PR.

\section{METHODS}

\section{DESIGN}

We used a one-group pre/post-test design (Shadish, Cook, \& Cambell, 2002). Participants were assessed at baseline (T1), immediately after the 8-week telerehabilitation program (T2), and 24 weeks (6 months) later (T3). All assessments were performed by an independent research assistant at the Centre hospitalier universitaire de Sherbrooke (CHUS) and were conducted under direct medical supervision. The study was approved by the CHUS and the Centre de santé et de services sociaux - Institut universitaire de gériatrie de Sherbrooke (CSSS-IUGS) ethics committees, and each participant provided signed informed consent. The project took place between August 2011 and July 2014.

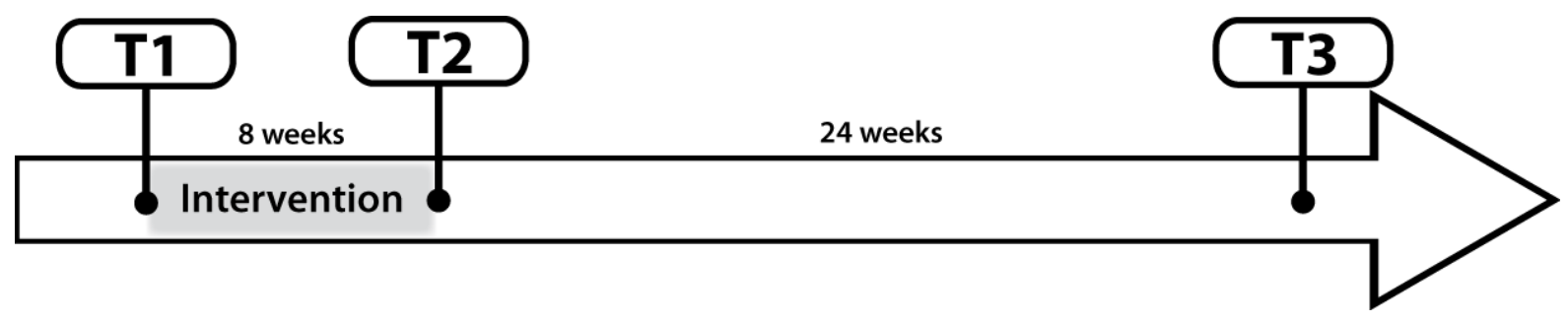

Figure 1. Study pre-experimental design.

\section{POPULATION AND SAMPLE}

The study population consisted of patients 40 years and older with a clinical diagnosis of COPD recruited from the CHUS outpatient respiratory clinic and from the waiting list for the outpatient COPD rehabilitation program. Inclusion criteria were: (1) having forced expiratory volume in one second $\left(\mathrm{FEV}_{1}\right)$ below $70 \%$ of predicted value and FEV1/FVC ratio less than 0.70 ; (2) being minimally symptomatic (patient breathlessness $\geq 2$ as assessed by the Medical Research Council dyspnea scale (O'Donnell et al., 2008)); (3) being a smoker or former smoker (10 pack-year of smoking history); (4) not having had a respiratory infection or exacerbation in the 4 weeks prior to the first assessment; (5) not having done PR in the previous 12 months; and (6) having access to a high speed Internet 
connection. Exclusion criteria were: (1) having significant cardiovascular disorders; (2) requiring long-term supplemental home oxygen; (3) having contraindications for physical exercise (neuromuscular, orthopedic conditions); and (4) being unable to understand the verbal or written program instructions or fill out questionnaires.

\section{EXERCISE PROGRAM OF THE PULMONARY TELEREHABILITATION}

The first component of the pulmonary telerahabilitation was exercises training. Based on previous studies (Tousignant, Boissy, Corriveau, \& Moffet, 2006; Tousignant et al., 2009, Tousignant et al., 2011), a telerehabilitation platform was developed and refined for the COPD treatments (Tousignant et al., 2012). The in-home PR exercise program combined cardiorespiratory endurance (aerobic) and strengthening. The cardiorespiratory training was performed on a stationary bicycle (ergocycle) with manually adjustable resistance at $60 \%$ of the maximum work rate achieved during a test of peak exercise capacity. It took place 3 times a week for 8 weeks with 10 to 40 minutes per session depending on the individual's physical condition.

The program lasted 8 weeks but teletreatments were gradually replaced by unsupervised treatments in order to develop the patients' motivation to do the exercises by themselves in the future. The schedule was the same for all participants: weeks 1 and 2: 3 teletreatments, none without supervision; weeks 3,4 , and 5: 2 teletreatments and 1 session without supervision; weeks 6,7 , and 8: 1 teletreatment and 2 sessions without supervision. Therefore, the whole program included 24 exercise sessions, 15 with telehealth technology and 9 unsupervised sessions (Bourbeau, 2010; Bourbeau, 2012).

\section{EDUCATIONAL PROGRAM OF PR}

The second component of the telehealth program was self-management education. It comprised written pamphlets and eight narrative health capsules (Table 1) that summarized the written material from "Living Well with COPD" (Bourbeau et al., 2009). They were available directly on the workstation of each participant by simply selecting the module on their computer's touch screen. Each narrative capsule lasted 15 to 20 minutes. Participants had access to a new self-learning capsule on their workstation every week and were able to listen to it at their convenience and as often as they wanted during the week. All the subjects offered in the context of this study are listed in Table 1. Furthermore, participants were encouraged to write down any questions that arose while viewing the capsule and the questions were answered by the health professional at the following teletreatment session. After the intervention period, the stationary bicycle was removed from the residence but participants could keep the exercise program and self-management written material. No formal maintenance strategy was planned during the 6-month follow-up period. Participants were simply encouraged to buy their own stationary bicycle, continue their programs as they were taught and consult the written material from "Living Well with COPD" as needed.

Table 1. Subject Presented in Each of the Eight Modules Offered in the PR Education from the "Living Well With COPD"

\begin{tabular}{ll}
\hline $\begin{array}{l}\text { Every week health } \\
\text { capsules }\end{array}$ & Subjects of the education program \\
\hline Module 1 & $\begin{array}{l}\text { Introduction to your exercise } \\
\text { program } \\
\text { Your breathing }\end{array}$ \\
Module 2 & Energy conservation techniques \\
Module 3 & Your symptoms \\
Module 4 & Your medication \\
Module 5 & Your action plan \\
Module 6 & Maintaining a health and satisfying \\
Module 7 & life style \\
Module 8 & Managing stress and anxiety
\end{tabular}

\section{DATA COLLECTION PROCEDURES}

An initial visit was scheduled to review the participant's medical history and obtain signed consent. Eligibility was confirmed by a medical evaluation and an incremental cycle test (Jones stage 1 protocol) (Jones, Makrides, Hitchcock, Chypchar, \& McCartney, 1985). All participants were assessed at baseline (T1), and effectiveness of the telerehabilitation was assessed immediately after the intervention (T2). Participants were then reassessed 6 months later (T3) to document maintenance.

\section{DEPENDENT VARIABLES}

Exercise tolerance was assessed using the 6MWT (Rasekaba, Lee, Naughton, Williams, \& Holland, 2009) and the CET (Casaburi, 2005) while quality of life was measured with the CRQ (Bourbeau, Maltais, Rouleau, \& Guimont, 2004). The 6MWT is frequently used to evaluate the functional capacity of patients with COPD (Celli et al., 2004; Rasekaba et al., 2009). The CET is a constant-load test performed on a stationary bicycle (Casaburi \& Porszasz, 2009; Laviolette et al., 2008). The constant-load intensity for 
the CET was established at $80 \%$ of the incremental cycle test done before entering the study (Jones et al., 1985). The Chronic Respiratory Questionnaire (CRQ) (Bourbeau et al., 2004) is divided into 4 domains: (1) dyspnea, (2) fatigue, (3) emotion, and (4) mastery. Each item is rated on a 7-point scale, and higher scores are associated with good quality of life (Bourbeau et al., 2004).

\section{STATISTICAL ANALYSIS}

Sociodemographic characteristics of the participants are presented with the usual descriptive statistics. Paired $t$ tests or Wilcoxon signed-rank, depending on the normality of the variables, were used to test changes during the intervention (T2-T1) and analyze changes during follow-up (T3-T2). Analyses were performed with SPSS 21.0. A conservative imputation method was used, in which T1

Table 2. Characteristics of the Study Participants $(n=23)$ scores replaced missing values at T2 and missing values at T3 were replaced by the worst value between T1 and T2 scores. Results were similar with or without imputation.

\section{RESULTS}

\section{PARTICIPANTS' CHARACTERISTICS}

Twenty-three participants with COPD were on average 65.2 years old (standard deviation $(\mathrm{SD})=7.1$ ) with forced expiratory volume in 1 second 47.7 (12.7) \% predicted (Table 2). The majority of the participants were women $(60$ $\%)$ and the mean year of schooling was 11 . From T1 to T2, one person did not complete the intervention because of an exacerbation. During the 6-month follow-up period five participants dropped out (35\%) due to an exacerbation. Finally, one participant did not perform the CET because of discomfort with the mask.

\begin{tabular}{|c|c|c|c|}
\hline & & Mean \pm SD & Range (min-max) \\
\hline \multicolumn{2}{|l|}{ Age (years) } & $65.2 \pm 7.1$ & $50-75$ \\
\hline \multicolumn{2}{|l|}{ BMI $\left(\mathrm{kg} / \mathrm{m}^{2}\right)$} & $27.0 \pm 5.8$ & $17.2-39.9$ \\
\hline \multicolumn{2}{|c|}{ MRC dyspnea scale ( /5) } & $3.5 \pm 0.5$ & $3-4$ \\
\hline \multicolumn{2}{|c|}{ FEV $_{1}$ (\% predicted) } & $47.7 \pm 12.7$ & $21-66$ \\
\hline \multicolumn{2}{|c|}{ FEV $_{1}$ - FVC ratio (\%) } & $51.5 \pm 13.8$ & $30-83$ \\
\hline \multirow{2}{*}{\multicolumn{2}{|c|}{ Schooling (years) }} & $10.9 \pm 2.6$ & $2-16$ \\
\hline & & Frequency & Percentage \\
\hline \multicolumn{2}{|l|}{ Women } & 15 & 60.0 \\
\hline \multirow[t]{3}{*}{ GOLD stage } & II (moderate) & 10 & 38.5 \\
\hline & III (severe) & 13 & 50.0 \\
\hline & IV (very severe) & 3 & 11.5 \\
\hline \multirow[t]{4}{*}{ Education level: } & Illiterate & 1 & 3.8 \\
\hline & Primary & 3 & 11.5 \\
\hline & Secondary & 20 & 76.9 \\
\hline & University & 2 & 7.7 \\
\hline \multicolumn{2}{|l|}{ Working } & 2 & 7.7 \\
\hline \multicolumn{2}{|l|}{ Living alone } & 10 & 38.5 \\
\hline \multicolumn{2}{|c|}{ Exacerbations (T1-T2) $n=23$} & 5 & 21.7 \\
\hline \multicolumn{2}{|c|}{ Exacerbations (T2-T3) $n=17$} & 6 & 35.4 \\
\hline
\end{tabular}

Note. SD: standard deviation; BMI: body mass index; MRC: Medical Research Council (dyspnea score); FEV ${ }_{1} \%$ : forced expiratory volume in one second, percent predicted; FVC: forced vital capacity; GOLD: global initiative for chronic obstructive lung disease (severity classification) 
EXERCISE TOLERANCE AND QUALITY OF LIFE

As can be seen in Figure 2, immediately after the PR intervention (T2-T1), participants had improved their walking distance and length of time on the stationary bicycle (Marquis et al., 2015). These differences were clinically and statistically significant at the 0.05 level. However, with respect to maintenance of improvements, exercise tolerance decreased significantly after 24 weeks (T3) for the 6MWT (mean (SD): - $28.0(35.0) \mathrm{m} ; \mathrm{p}<0.001)$ as well as for the CET (median (EQI): - 33.0 (-91.5; 0.0) s; p = 0.003). Comparing T3 to T1 showed that values returned to near baseline measures $(p=0.618$ for the 6MWT and $p=0.609$ for the CET).

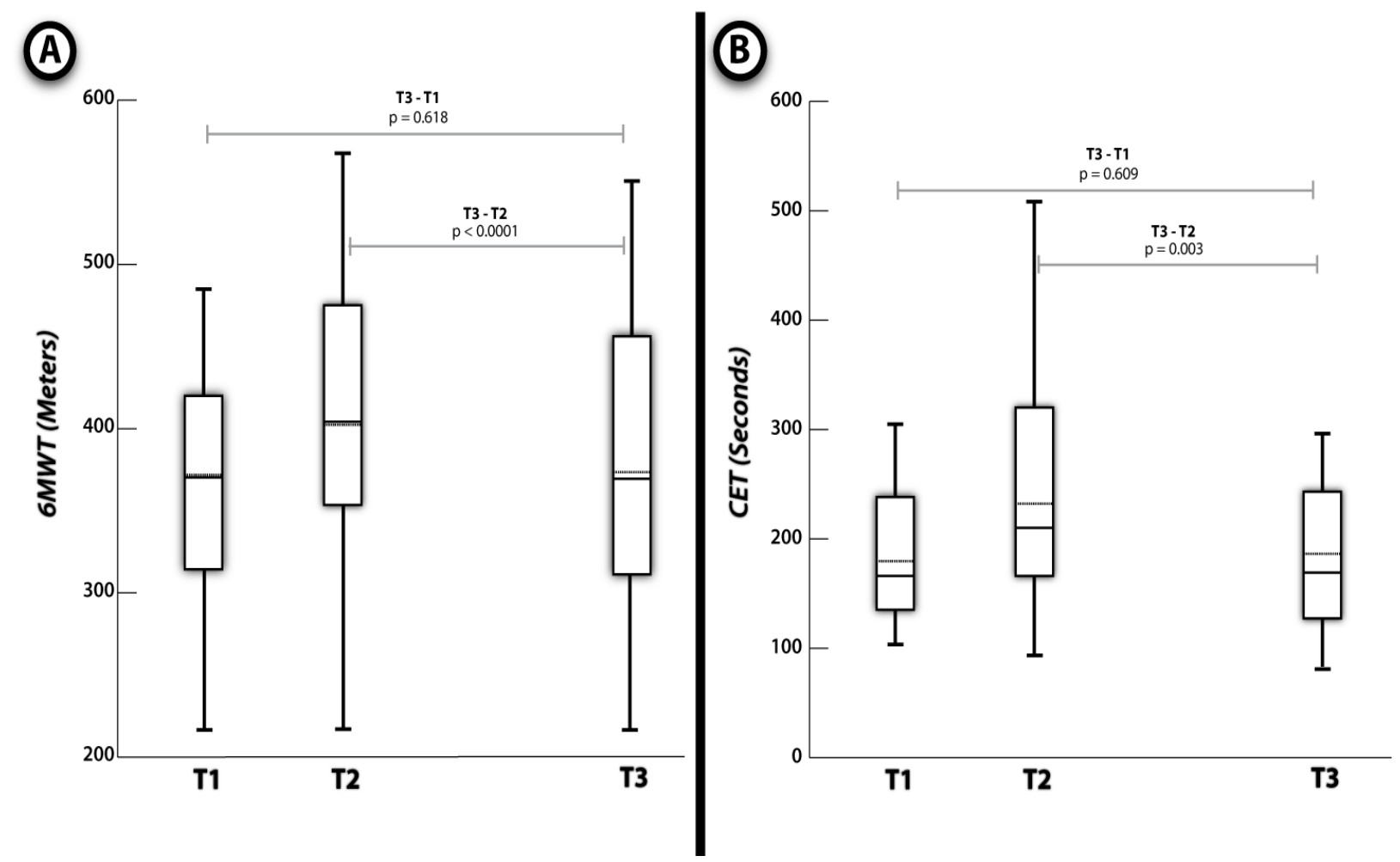

Figure 2. Changes in A. 6MWT, walking distance and B. CET, endurance time immediately after a pulmonary telerehabilitation intervention and 6 months later (gray lines inside the boxes are means, black lines are medians).

Quality of life improved significantly after the intervention (T2-T1) for three out of four domains of the CRQ (dyspnea, fatigue and emotion). However, none of these changes were still present 24 weeks later, with a significant decrease of values and return to baseline performance for each domain of the CRQ (Figure 3). 

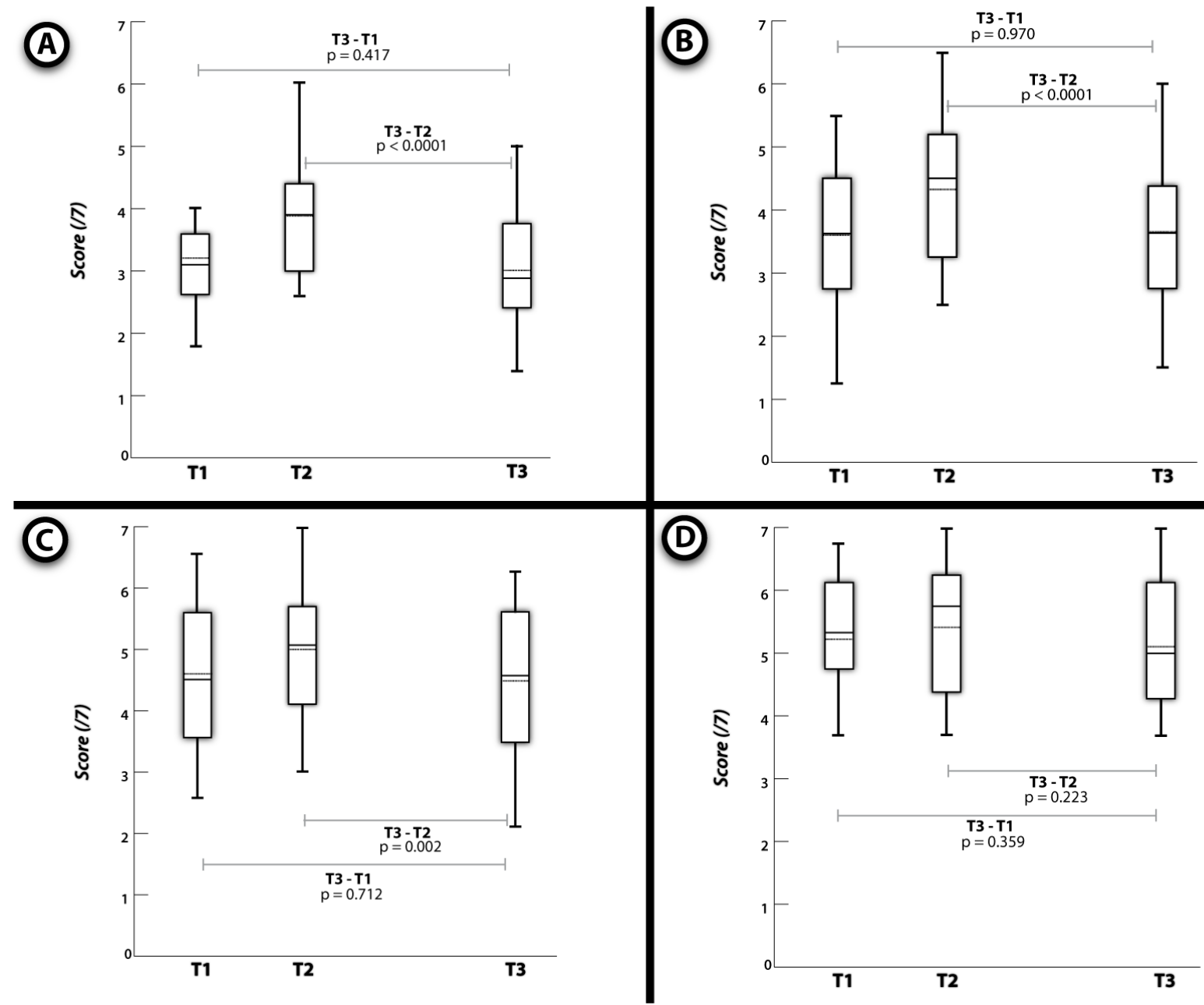

Figure 3. Changes in the four domains (A. dyspnea, B. fatigue, C. emotion and D. mastery) of the CRQ immediately after a pulmonary telerehabilitation intervention and 6 months later (gray lines inside the boxes are means, black lines are medians).

\section{DISCUSSION}

The objective of this study was to investigate if changes in exercise tolerance and quality of life obtained with pulmonary telerehabilitation could be maintained over the long-term. We implemented two strategies aimed at sustaining the pursuit of exercise and adequate selfmanagement of COPD after treatment: self-management education via health capsules and progressive withdrawal of supervised treatment (telerehabilitation) combined with unsupervised sessions. To our knowledge, this is the first study to investigate a complete PR program (exercises and education) delivered entirely by telehealth technology and assess maintenance six months later for patients with COPD. Short-term improvements however, decreased significantly after 24 weeks and, in fact, returned to near

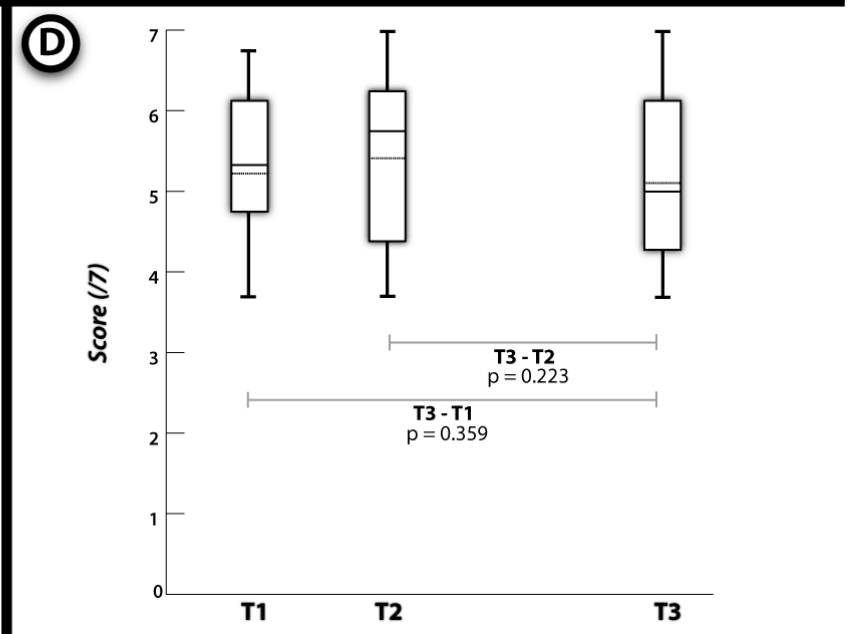


To obtain and maintain behavioral changes and get better and lasting results after a PR intervention, Effing et al. (2012) recently reported the importance of combining exercise training with self-management interventions. Our results show that a PR intervention using telehealth technology has positive effects on exercise tolerance and quality of life. However, even though participants were encouraged to do the exercises by themselves by decreasing the number of supervised telerehabilitation sessions, patients probably did not have the chance to build sufficient self-confidence to be able to pursue their program by themselves. To change behaviour, participants had to understand the benefits and build the confidence to be able to self-manage their illness (Bourbeau \& Nault, 2007). This leads patients to believe in their own ability to successfully change behavior, which is essential to achieve concrete long-term beneficial health effects (Benzo et al., 2013; Bourbeau \& Nault, 2007; Lorig \& Holman, 2003). Bandura's theory of self-efficacy (Bandura, 1977) defines the sense of self-confidence (self-efficacy) as the belief that a person has in respect to his or her ability and competence to do the necessary actions in response to a specific situation. It can be summarized in terms of four main pillars (Bandura, 2007), the first being performance or the ability to successfully complete a task. In that matter, the therapist can divide tasks into steps to promote learning success. The second pillar is modeling or emulating someone else. The patient learns a lot by observing another patient's progress. The third pillar is verbal persuasion. The patient needs feedback (positive reinforcement) to make behavior changes and also follow-up to persevere in applying the new tasks learned in everyday life (Bourbeau \& Nault, 2007;

Weingarten et al., 2002). The last pillar concerns patients' physical and psychological condition (i.e., they must feel physically and emotionally able to cope with demands). Managing their anxiety, stress and dyspnea when dealing with challenges will help patients improve their performance and confidence in self-managing their illness (Bandura, 1977).

As summarized in the self-management model adapted from Bourbeau and Nault (2007) in Figure 4, selfmanagement means using the gained knowledge and acquired skills to build confidence in one's abilities (selfefficacy). Self-efficacy fosters the adoption of new behaviors (using the four pillars of Bandura's theory) that will be integrated in everyday life (behavior change) to produce a positive impact on health and quality of life (Bourbeau \& Nault, 2007).

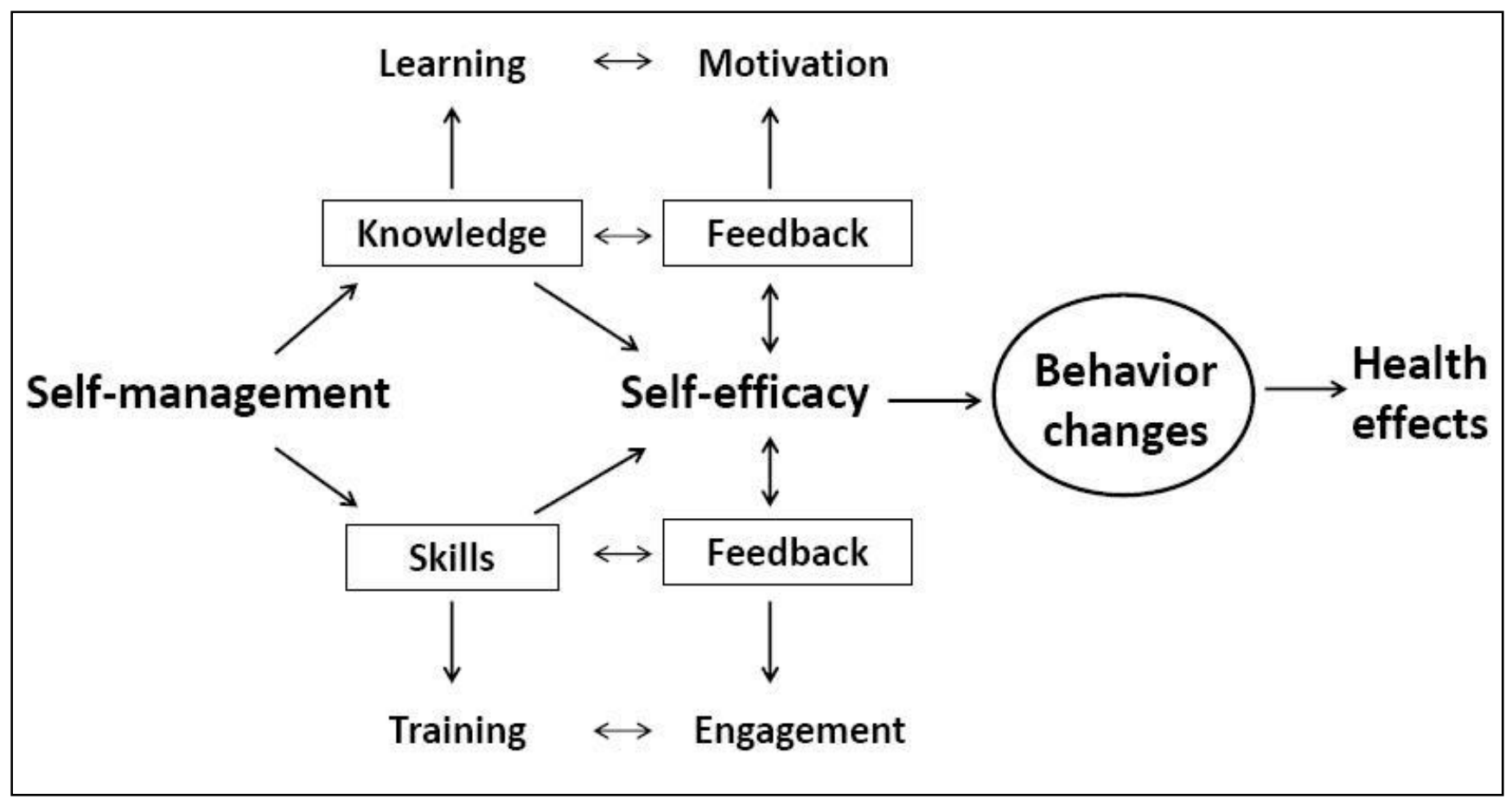

Figure 4. Self-management model adapted from Bourbeau and Nault (2007). 
Also, Bourbeau and Nault (2007) pointed out, as did Bandura (1977), the importance of feedback given to the participant. Participants need to know what they are doing well and what they are doing wrong. Positive reinforcement increases motivation and self-confidence while it is also important to reassure participants during negative experiences. Sharing with an expert, modeling one's behavior on someone else and feedback are all tools that can help empower patients to believe in their own capacity to continue to change by themselves over the long term (Bandura, 1977).

\section{LIMITATIONS}

Our study has some limitations. First, we acknowledge that we cannot affirm that our education method really had some impact on participants' knowledge. Our teleeducational program did not include performance assessment of knowledge or skills acquisition. Moreover, no learning questionnaire was used to measure how much knowledge was acquired. Such questionnaires could help health professionals ensure that educational aspects are integrated by patients and that they are able to use those skills in everyday life. The last aspect that needs to be improved for future research is having a follow-up strategy that could be applied over the long term at low cost. For example, at the end of a PR program, patients could stay in touch with their health professional via an official website and interact online by chatting or emailing every week. This aspect will have to be developed in the future to optimize PR delivered by telehealth technology.

Another point that could have had a negative impact on maintenance is the fact that the stationary bicycle was removed from the residence at the end of the intervention. Even though the adherence of the unsupervised sessions was very good during the program, we do not know if participants bought a bicycle after the program to continue the exercise training by themselves.

\section{CONCLUSION}

An online PR program that includes exercise training and self-management education is a practical way to provide people with moderate to very severe COPD with access to services. For future research, knowledge acquisition assessment and structured feedback should be considered to enhance the long-term effectiveness of a PR program that employs telehealth technology. For example, an adaptation of Bourbeau and Naud's (2007) model could be employed in the context of a virtual self-management educational program in which patients continue their exercise programs to achieve long term, better maintenance (Spruit et al., 2013).

\section{FUNDING SOURCE}

The Canadian Institutes of Health Research (CIHR) provided funding for this study.

\section{ACKNOWLEDGEMENTS}

The authors acknowledge the help from the following: the team of respiratory therapists of the CHUS in charge of spirometry and cycle testing; respirologists from the pulmonary clinic at the CHUS who supervised the tests; research assistants from the Research Centre on Aging; therapists who delivered the teletreatment sessions, and the engineering staff.

\section{REFERENCES}

Bandura, A. (1977). Self-efficacy: Toward a unifying theory of behavioral change. Psychological Review, 84, 191215.

Bandura, A. (2007). Auto-efficacité : Le sentiment d'efficacité personnelle (2nd ed.). Paris: De Boeck.

Benzo, R., Vickers, K., Ernst, D., Tucker, S., McEvoy, C., \& Lorig, K. (2013). Development and feasibility of a selfmanagement intervention for chronic obstructive pulmonary disease delivered with motivational interviewing strategies. Journal of Cardiopulmonary Rehabilitation and Prevention, 33, 113-123.

Bourbeau, J. (2010). Making pulmonary rehabilitation a success in COPD. Swiss Medical Weekly, 140, e1-e8.

Bourbeau, J. (2012, mai). La réadaptation pulmonaire au Québec "D'hier à demain". Présentation faite pour le Réseau Québécois de l'Asthme et de la MPOC (RQAM). Paper presented at the Présentation faite pour le Réseau Québécois de l'Asthme et de la MPOC (RQAM).

Bourbeau, J., Julien, M., Maltais, F., Rouleau, M., Beaupré, A., Bégin, R., ... Collet, J. (2003). Reduction of hospital utilization in patients with chronic obstructive pulmonary disease: A disease-specific self-management intervention. Archives of Internal Medicine, 163, 585591.

Bourbeau, J., Maltais, F., Rouleau, M., \& Guimont, C. (2004). French-Canadian version of the Chronic Respiratory and St George's Respiratory questionnaires: An assessment of their psychometric properties in patients with chronic obstructive pulmonary disease. Canadian Respiratory Journal, 11, 480-486.

Bourbeau, J., \& Nault, D. (2007). Self-management strategies in chronic obstructive pulmonary disease. Clinics in Chest Medicine, 28, 617-628. 
Bourbeau, J., Nault, D., Parenteau, S., Bernard, S., Desgagné, P., Devost, A., ... Frennete, J. (2009). Mieux vivre avec une maladie pulmonaire obstructive chronique (MPOC) Un plan d'action pour la vie Intégrer un programme d'exercices dans votre vie: RQAM Editor.

Bourbeau, J., \& van der Palen, J. (2009). Promoting effective self-management programmes to improve COPD. European Respiratory Journal, 33, 461-463.

Casaburi, R. (2005). Factors determining constant work rate exercise tolerance in COPD and their role in dictating the minimal clinically important difference in response to interventions. COPD, 2, 131-136.

Casaburi, R., \& Porszasz, J. (2009). Constant work rate exercise testing: A tricky measure of exercise tolerance. COPD, 6, 317-319.

Celli, B. R., Cote, C. G., Marin, J. M., Casanova, C., Montes de Oca, M., Mendez, R. A., . . Cabral, H. J. (2004). The body-mass index airflow obstruction dyspnea and exercise capacity index in chronic obstructive pulmonary disease. New England Journal of Medicine, 350, 1005-1012.

Effing, T. W., Bourbeau, J., Vercoulen, J., Apter, A. J., Coultas, D., Meek, P., . . . Palen, J. (2012). Selfmanagement programmes for COPD: Moving forward. Chronic Respiratory Disease, 9, 27-35.

Jones, N., Makrides, L., Hitchcock, C., Chypchar, T., \& McCartney, N. (1985). Normal standards for an incremental progressive cycle ergometer test. American Review of Respiratory Disease, 131, 700-708.

Labrecque, M., Rabhi, K., Laurin, C., Favreau, H., Moullec, G., Lavoie, K., \& Julien, M. (2011). Can a selfmanagement education program for patients with chronic obstructive pulmonary disease improve quality of life? Canadian Respiratory Journal, 18, e77-e81.

Lacasse, Y., Maltais, F., \& Goldstein, R. S. (2004). Pulmonary rehabilitation: An integral part of the longterm management of COPD. Swiss Medical Weekly, 134, 601-605.

Lacasse, Y., Martin, S., Lasserson, T. J., \& Goldstein, R. S. (2007). Meta-analysis of respiratory rehabilitation in chronic obstructive pulmonary disease: A Cochrane systematic review. Europa Medicophysica, 43, 475-485.

Lacasse, Y., Wong, E., Guyatt, G. H., King, D., Cook, D. J., \& Goldstein, R. S. (1996). Meta-analysis of respiratory rehabilitation in chronic obstructive pulmonary disease. Lancet, 348, 1115-1119.

Laviolette, L., Bourbeau, J., Bernard, S., Lacasse, Y., Pepin, V., Breton, M., ... Maltais, F. (2008). Assessing the impact of pulmonary rehabilitation on functional status in COPD. Thorax, 63, 115-121.
Lorig, K. R., \& Holman, H. (2003). Self-management education: History definition outcomes and mechanisms. Annals of Behavioral Medicine, 26, 1-7.

Lorig, K. R., Ritter, P. L., Laurent, D. D., \& Plant, K. (2006). Internet-based chronic disease self-management: A randomized trial. Medical Care, 44, 964-971.

Maltais, F., Bourbeau, J., Shapiro, S., Lacasse, Y., Perrault, H., Baltzan, M., . . . Bernard, S. (2008). Effects of home-based pulmonary rehabilitation in patients with chronic obstructive pulmonary disease: A randomized trial. Annals of Internal Medicine, 149, 869-878.

Marquis, N., Larivée, P., Saey, D., Dubois, M.-F., \& Tousignant, M. (2015; accepted). In-home pulmonary telerehabilitation for patients with Chronic Obstructive Pulmonary Disease (COPD): A pre-experimental study on effectiveness satisfaction and adherence.

Telemedicine and e-Health.

Moroz, M. S. A. (2007). La prise en charge de la maladie chronique. Améliorer les soins prodigués aux patients souffrant de maladies chroniques: modèle de soins de longue durée. Actualités de réadaptation cardiaque et de prévention de la maladie cardiovasculaire, 15, 1-4.

Nguyen, H. Q., Carrieri-Kohlman, V., Rankin, S. H., Slaughter, R., \& Stulbarg, M. S. (2005). Is Internetbased support for dyspnea self-management in patients with chronic obstructive pulmonary disease possible? Results of a pilot study. Heart \& Lung: The Journal of Critical Care, 34, 51-62.

Nguyen, H. Q., Donesky-Cuenco, D., Wolpin, S., Reinke, L. F., Benditt, J. O., Paul, S. M., \& Carrieri-Kohlman, V. (2008). Randomized controlled trial of an Internet-based versus face-to-face dyspnea self-management program for patients with chronic obstructive pulmonary disease: pilot study. Journal of Medical Internet Research, 10, e9.

O'Donnell, D. E., Hernandez, P., Kaplan, A., Aaron, S., Bourbeau, J., Marciniuk, D., ... Voduc, N. (2008). Canadian Thoracic Society recommendations for management of chronic obstructive pulmonary disease - 2008 update - highlights for primary care. Canadian Respiratory Journal, 15(Suppl A), 1A-8A.

Rasekaba, T., Lee, A. L., Naughton, M. T., Williams, T. J., \& Holland, A. E. (2009). The six-minute walk test: A useful metric for the cardiopulmonary patient. Internal Medicine Journal, 39, 495-501.

Ries, A., Kaplan, R., Limberg, T., \& Prewitt, L. (1995). Effects of pulmonary rehabilitation on physiologic and psychosocial outcomes in patients with chronic obstructive pulmonary disease. Annals of Internal Medicine, 122, 823-832.

Shadish, W. R., Cook, T. D., \& Cambell, D. T. (2002). Experimental and quasi-experimental designs for generalized causal inference. Boston. MA, U.S.A.: Houghton Mifflin Company. 
Spruit, M. A., Singh, S. J., Garvey, C., ZuWallack, R., Nici, L., Rochester, C., . . Rehabilitation, A.E.T.F.o.P. (2013). An official American Thoracic Society/European Respiratory Society statement: key concepts and advances in pulmonary rehabilitation. American Journal of Respiratory and Critical Care Medicine, 188, e13-64.

Stickland, M., Jourdain, T., Wong, E. Y., Rodgers, W. M., Jendzjowsky, N. G., \& Macdonald, G. F. (2011). Using telehealth technology to deliver pulmonary rehabilitation in chronic obstructive pulmonary disease patients. Canadian Respiratory Journal, 18, 216-220.

Strijbos, J. H., Postma, D. S., van Altena, R., Gimeno, F., \& Koëter, G. H. (1996). A comparison between an outpatient hospital-based pulmonary rehabilitation program and a home-care pulmonary rehabilitation program in patients with COPD: A follow-up of 18 months. Chest, 109, 366-372.

Tousignant, M., Boissy, P., Corriveau, H., \& Moffet, H. (2006). In home telerehabilitation for older adults after discharge from an acute hospital or rehabilitation unit: $A$ proof-of-concept study and costs estimation. Disability and Rehabilitation: Assistive Technology, 1, 209-216.

Tousignant, M., Moffet, H., Boissy, P., Corriveau, H., Cabana, F., \& Marquis, F. (2009). In home telerehabilitation for post-knee artroplasty: A pilot study. International Journal of Telerehabilitation, 1(1), 9-16.
Tousignant, M., Moffet, H., Boissy, P., Corriveau, H., Cabana, F., \& Marquis, F. (2011). A randomized controlled trial of home telerehabilitation for post-knee arthroplasty. Journal of Telemedicine and Telecare, 17, 195-198.

Tousignant, T., Marquis, N., Pagé, C., Imukuse, N., Metivier, A., St-Onge, V., \& Tremblay, A. (2012). In-home telerehabilitation for older persons with chronic obstructive pulmonary disease: A pilot study. International Journal of Telerehabilitation, 4(1), 7-13.

Weingarten, S. R., Henning, J. M., Badamgarav, E., Knight, K., Hasselblad, V., Gano, A., \& Ofman, J. J. (2002). Interventions used in disease management programmes for patients with chronic illness-which ones work? Meta-analysis of published reports. British Medical Journal (clinical research ed.), 325, 925.

Wijkstra, P. J., Ten Vergert, E. M., van Altena, R., Otten, V., Kraan, J., Postma, D. S., \& Koëter, G. H. (1995). Long term benefits of rehabilitation at home on quality of life and exercise tolerance in patients with chronic obstructive pulmonary disease. Thorax, 50, 824-828. 